\title{
Chapter 2 Health risk behaviors and emotional state of medical students
}

Capítulo 2 Conductas de riesgo para la salud y el estado emocional de los estudiantes de medicina

GONZÁLEZ-RAMÍREZ, Leivy Patricia'†*, MERAZ-MEDINA, Tzintli”, CHÁVEZ-TOSTADO, Mariana Guadalupe"" and GONZÁLEZ-HEREDIA, Tonatiuh"'"

'School of Medicine and Health Science, Campus Guadalajara, Tecnólogico de Monterrey.

"Department of Basic Science of Health, University Center of South, Universidad de Guadalajara.

"'Department of human reproduction, growth and child development, University Center of Health Science, Universidad de Guadalajara.

"'"Department of Biomedical Sciences, University Center of Tonalá, Universidad de Guadalajara.

ID $1^{\text {st }}$ Author: Leivy Patricia, Gonález-Ramírez / ORC ID: 0000-0002-2952-2836, CVU CONACYT ID: 426755

ID $1^{\text {st }}$ Co-author: Tzintli, Meraz-Medina / ORC ID: 0000-0002-2062-8618, CVU CONACYT ID: 131300

ID $2^{\text {nd }}$ Co-author: Mariana Guadalupe, Chávez-Tostado / ORC ID: 0000-0002-2308-6105, CVU CONACYT ID: 509855

ID $3^{\text {rd }}$ Co-author: Tonatiuh, González-Heredia / ORC ID: 0000-0003-4089-5462, CVU CONACYT ID: 386340

DOI: $10.35429 /$ H.2021.13.11.19

L. González, T. Meraz, M. Chávez and T. González

* tzintli.meraz@cusur.udg.mx

A. Marroquín, J. Olivares, M. Cruz, L. Cruz. (Coord.) CIERMMI Women in Science TXIII Medicine and Health Sciences. Handbooks-@ECORFAN-México, Querétaro, 2021. 


\begin{abstract}
The promotion of healthy lifestyles amongst medical students is important in reducing alterations in their emotional state and the creation of healthier habits which, when adopted at this stage, could influence the promotion of better lifestyles for their patients. This current study intends to evaluate health risk behaviors and their relationship with the emotional state in medical students. An analytical crosssectional study was carried out, evaluating 173 students of a public university between January and March of 2019, evaluating anxiety (Beck Anxiety Inventory, BAI), depression (Beck Depression Inventory, BDI-II), alcohol and nicotine dependence (Alcohol Use Disorders Identification Test, AUDIT, Fagerström Physical Nicotine Dependence), and Body mass index (BMI). sociodemographic and clinical data was collected through an interview. An association was found between anxiety and a sedentary $(\mathrm{p}$ $=0.01, \mathrm{OR}=0.446, \mathrm{CI}=0.24-0.83)$, and depression with alcohol consumption $(\mathrm{p}=0.005, \mathrm{OR}=2.972$, $\mathrm{CI}=1.36-6.49)$. During college students face various demands that can unleash alterations in their emotional and physical state, the results obtained in this study allow the development of intervention programs against risky behaviors and promote healthy lifestyles.
\end{abstract}

\title{
Lifestyles, Emotional state, Medical students
}

\section{Resumen}

La promoción de estilos de vida saludables entre estudiantes de medicina es importante para reducir riesgos de enfermedades y alteraciones del estado emocional. Este estudio pretende evaluar conductas de riesgo para la salud y su relación con el estado emocional en estudiantes de medicina. En un estudio analítico transversal, se evaluó 173 estudiantes de una Universidad pública en el periodo de enero - marzo del 2019, considerando ansiedad (Beck Anxiety Inventory, BAI), depresión (Beck Depression Inventory, BDI-II), dependencia al alcohol (Alcohol Use Disorders Identification Test, AUDIT), a nicotina (Fagerström Physical Nicotine Dependence) e índice de masa corporal (IMC). Mediante entrevista se recabaron datos clínicos y sociodemográficos. Los resultados del estudio mostraron asociación entre ansiedad y sedentarismo $(\mathrm{p}=0,01, \mathrm{OR}=0,446, \mathrm{CI}=0,24-0,83)$, y depresión con consumo de alcohol $(\mathrm{p}=0,005, \mathrm{OR}=2,972, \mathrm{CI}=1,36-6,49)$. Se observa una diferencia entre géneros al considerar el estado emocional, donde las mujeres tienen mayor prevalencia de ansiedad y depresión. Durante la universidad los estudiantes enfrentan diversas exigencias, que pueden desencadenan alteraciones del estado emocional y físico, los resultados obtenidos en este estudio permitirán elaborar programas de intervención contra conductas de riesgo y promover estilos de vida saludables.

\section{Estilos de vida, Estado emocional, Estudiantes de medicina}

\subsection{Introduction}

Inadequate lifestyles have been associated with the development of mental disorders such as stress and anxiety, which represent some of the main causes of death around the world (Alzahrani et al., 2019). Recent data demonstrates that these diseases have begun to affect younger and younger generations (Almutairi et al., 2018). Encouraging the inclusion of healthy behaviors within the lifestyle, such as physical activity, eating a healthy diet, avoiding the use of substances such as tobacco or drugs and having a restful sleep, can promote the health and well-being of these individuals (Lolokote, Hidru, \& Li, 2017; Pacheco, Santos-Silva, Gordia, de Quadros, \& Petroski, 2014). However, the manner in which an individual's lifestyle is practiced is very much influenced by the culture, beliefs and motivation of those individuals (Rodriguez-Gazquez, Chaparro-Hernandez, \& Gonzalez-Lopez, 2016).

Anxiety and depression are the psychological disorders with the greatest impact upon public health and which have also been associated with an unhealthy lifestyle (Sharma et al., 2016). For example, ample evidence has shown the benefits of physical activity for potentially avoiding or reducing the symptoms of anxiety and depression (Hyakutake et al., 2016, Velten, Bieda, Scholten, Wannemuller, \& Margraf, 2018). Sedentarism, smoking and alcohol consumption have also been associated with the development of depression and anxiety (Rao, Shah, Jawed, Inam, \& Shafique, 2015, Saneei et al., 2016). University students are at a stage in their lives which involve certain changes to their lifestyles, the development of new social networks and greater autonomy in their self-care (Almutairi et al., 2018). 
These changes are often influenced by social factors, such as income or interpersonal relationships. This may be the period in which many adolescents incorporate risk behaviors such as alcohol, tobacco, drugs, risk sexual behavior, sedentary lifestyle and poor eating and sleep habits, among others that could increase the amounts of stress (Almutairi et al., 2018; Cezaretto, Ferreira, Sharma, Sadeghirad, \& Kolahdooz, 2017; Nogueira et al., 2018). In addition, risk behaviors which are initiated at this stage can be perpetuated throughout adulthood (Kim, 2018, Lolokote et al., 2017). In a study conducted by Rao (2015) it was observed that adolescents who had four or more risk behaviors were also twice as likely to have associated mental disorders.

For these reasons, it is important to evaluate health behaviors in university students, to detect the main problems and be able to implement health promotion programs in this population (Lolokote et al., 2017), especially when we take into account that these individuals are at a stage where the acquisition and maintenance of healthy lifestyle habits is critical (Cezaretto et al., 2017). This is particularly important considering that these medical students will be responsible for promoting such healthy behaviors in the future (Zarrazquin et al., 2014). Studies have shown that the practice of healthy behaviors amongst physicians also has an impact upon the attitudes and motivations of their patients towards preventive actions and the adoption of healthy lifestyles (Yu et al., 2015). The objective of this study was to evaluate behaviors which pose a potential risk to health and to know if they are in any way related to the emotional state, particularly to the presence of anxiety and depression amongst medical students.

\subsection{Methods}

\subsubsection{Study design and participants}

An analytical cross-sectional study was carried out between January and March of 2019. A representative sample of 173 public university students was used out of a population of 1,000 students, with a margin of error of $10 \%$ and a confidence level of $99 \%$. Both men and women were included, from all grades of medical school, with ages between 18 and 30 years. Students with previous diagnosis of anxiety, depression or some other psychiatric disorder were not included, nor those who were receiving any medical treatment.

\subsubsection{Instruments}

The sociodemographic and clinical data of the patients was collected through an interview. In addition, the weight and height of the students were measured to calculate the Body Mass Index (BMI).

The "Beck Anxiety Inventory (BAI)" was used to measure anxiety. This tool consists of 21 items, with a score ranging between 0 and 63. A score between 0 and 7 corresponds to a normal level of anxiety while scores of 8 to 15,16 to 25 and 26 to 63 correspond to mild, moderate and severe levels of anxiety, respectively. It has a reliability of $\alpha=0,83$ (Robles, Varela, Jurado, \& Páez, 2001).

The Beck Depression Inventory (BDI-II) was used to measure depression. This tool consists of 21 items with four response options each. It has been validated in the Mexican population, and has a satisfactory internal consistency, both for the general factor $(\alpha=0,9)$, and for each of the factors with 0,85 in the cognitive-affective dimension and 0,78 in the somatic-motivational dimension (AcostaRodríguez, Rivera-Martínez, \& Pulido-Rull, 2011, González, Reséndiz-Rodríguez, \& Reyes-Lagunes, 2015).

The "Alcohol Use Disorders Identification Test (AUDIT)" was used to measure behaviors which may have an impact on health. This tool contains 10 questions that identify the use of alcohol in the last 12 months. Questions 4-6 identify the symptoms of alcohol dependence while questions 7-10 explore the negative consequences associated with alcohol consumption. Each question has three to five possible answers that can give a maximum score of 40 points. Based on the scores, an abstemious or low risk person can be identified by obtaining a score between 0 to 7 , while 8 to 12 points indicates a person with risky use or alcohol abuse and 13 to 40 points indicates probable dependence. AUDIT has been tested in the Mexican population with a sensitivity of $90 \%$ and specificity of $94 \%$. Different studies have validated it in adolescent populations, which report it as the best instrument for the identification of consumption and problems or disorders related to alcohol use in this type of population (Medina-Mora, Castro, Campillo-Serrano, \& Gómez-Mont, 1981; Mora-Rios \& Natera, 2001). 
On the other hand, the Fagerström Physical Nicotine Dependence Scale was also used. This tool contains six questions which consider the number of cigarettes consumed, the compulsion to use and abstinence. The results are established on a scale of 0 to 10 points. The tool categorizes an individual into 1 of 3 groups according to the score obtained. The physical dependence upon nicotine is categorized into mild $0-3$ points, moderate $4-7$ points, and severe $8-10$ points. This tool has demonstrated an internal consistency between 0,55 and 0,74 , with a standard of 0,72 , and stability around 0,58 and 0,91 in different samples (Moreno-Coutiño \& Villalobos-Gallegos, 2017, Paz-Ballesteros, Zavala-Arciniega, GutiérrezTorres, Ponciano-Rodríguez, \& Reynales-Shigematsu, 2019).

Finally, physical activity was considered to be adequate when an individual reported at least 30 minutes of exercise a day.

\subsubsection{Ethical considerations}

Informed consent was obtained from all students who were evaluated for this study. This was considered a low risk study given the fact that only non-invasive evaluations were performed. A number was assigned to each participant to comply with the confidentiality criteria. In addition, all ethical principles put forth by the declaration of Helsinki were followed.

\subsubsection{Statistical analysis}

The qualitative variables included sociodemographic characteristics such as sex, current year of medical school and marital status; emotional state: anxiety and depression and health-risk behaviors such physical activity, nicotine dependence, risk alcohol consumption, overweight and obesity. These were analyzed using frequencies and percentages, as well as mean and standard deviation for quantitative variables (age). The chi square or the Fisher exact statistical test was used to know if there were any differences due to the presence of anxiety, depression or gender. Additionally, the Odds Ratio (OR) was estimated for the groups where there were significant differences. Statistical analyses were carried out using a SPSS software (version 19) and the values of $\mathrm{p}<0.05$ were considered significant

\subsection{Results}

A total of 173 medical students were evaluated, of which $125(72,3 \%)$ were women and $48(27,7 \%)$ were men. The average age was 20.9 years $(\mathrm{SD}=2,2) .63,3 \%$ studied the first or second year of their medical training, 23,7\% the third or fourth year and $12,7 \%$ the fifth year or sixth year. $86,1 \%$ dedicated their time exclusively to studying. Of the students who were evaluated, $114(65,9 \%)$ were single, $55(31,8 \%)$ were engaged and only $4(2,3 \%)$ were married.

Regarding mental health, 103 students (59,5\%) presented anxiety and 48 (27\%) showed depression. Regarding unhealthy lifestyle behaviors which could pose potential physical and mental risk factors, 97 students $(56,1 \%)$ were sedentary, $1(0,6 \%)$ had nicotine dependence, $34(19,7 \%)$ reported risk alcohol consumption, 38 (22\%) were overweight and $15(8,7 \%)$ were obese.

Analyzing the relationships within this data, statistically significant differences were observed between sedentary individuals and those who performed regular physical activity in relation to anxiety, with a $\mathrm{p}=0,01$ and an $\mathrm{OR}=0,446(\mathrm{CI}=0,24-0,83)$. Regarding depression, differences were found between those with risk alcohol consumption habits and those who did not have any problems with alcohol consumption, with a $\mathrm{p}=0,005$ and an OR of 2,972 ( $\mathrm{CI}=1,36-6,49)$. No differences were observed regarding the variables of psychological state and tobacco consumption, although it should be noted that only one individual of those evaluated had nicotine dependence. No statistically significant differences were observed regarding the classification of Body Mass Index (Table 2.1). 
Table 2.1 Anxiety, depression and health risk behavior

\begin{tabular}{|c|c|c|c|c|c|c|}
\hline \multicolumn{4}{|c|}{ Anxiety } & \multicolumn{3}{|c|}{$\begin{array}{c}\text { Depression } \\
\text { n }(\%)\end{array}$} \\
\hline Variable & Without & With & $\mathbf{P}$ & Without & With & $\mathbf{p}$ \\
\hline \multicolumn{7}{|l|}{ Sedentarism } \\
\hline Present & $31(44)$ & $66(64)$ & \multirow[t]{2}{*}{$0,01 * *$} & $67(54)$ & $30(62)$ & \multirow[t]{2}{*}{0,291} \\
\hline Absent & $39(56)$ & $37(36)$ & & $58(46)$ & $18(38)$ & \\
\hline \multicolumn{7}{|l|}{ Smoking } \\
\hline Present & $70(0)$ & $102(99)$ & \multirow[t]{2}{*}{0,595} & $125(100)$ & $47(99)$ & \multirow[t]{2}{*}{0,277} \\
\hline Absent & $0(0)$ & $1(1)$ & & $0(0)$ & $1(1)$ & \\
\hline \multicolumn{7}{|c|}{ Excessive Alcohol Consumption } \\
\hline Present & $10(14)$ & $24(23)$ & \multirow[t]{2}{*}{0,143} & $18(14)$ & $16(33)$ & \multirow[t]{2}{*}{$0,005 * *$} \\
\hline Absent & $60(86)$ & $79(77)$ & & $107(86)$ & $32(67)$ & \\
\hline \multicolumn{7}{|l|}{ BMI } \\
\hline Low Weight & $4(6)$ & $3(3)$ & \multirow[t]{3}{*}{0,586} & $5(4)$ & $2(4)$ & \multirow[t]{3}{*}{0,276} \\
\hline Normal Weight & $46(65)$ & $67(65)$ & & $86(69)$ & $27(56)$ & \\
\hline $\begin{array}{l}\text { Overweight or } \\
\text { Obesity }\end{array}$ & $20(29)$ & $33(32)$ & & $34(27)$ & $19(40)$ & \\
\hline
\end{tabular}

\section{Source: Own elaboration}

When analyzing emotional state in relation to the sociodemographic variables, particularly gender, $(\mathrm{p}=0,002)$ anxiety and depression were found to be more prevalent among women than men with (62\% vs. $46 \%)$ and (34\% vs. $10 \%)$, respectively (Table 2.2$)$.

Table 2.2 Anxiety, depression and gender

\begin{tabular}{|c|c|c|c|c|}
\hline & $\begin{array}{r}\text { Feminine } \\
\text { n ( } \%)\end{array}$ & $\begin{array}{c}\text { Masculine } \\
\text { n }(\%)\end{array}$ & $\mathbf{p}$ & $\begin{array}{l}\text { OR } \\
\text { (CI) }\end{array}$ \\
\hline \multicolumn{5}{|l|}{ Anxiety } \\
\hline Present & $77(62)$ & $22(46)$ & \multirow[t]{2}{*}{0,372} & \\
\hline Absent & $48(38)$ & $26(54)$ & & \\
\hline \multicolumn{5}{|l|}{ Depression } \\
\hline Present & $43(34)$ & $5(10)$ & \multirow[t]{2}{*}{$\mathbf{0 , 0 0 2} * *$} & 0,22 \\
\hline Absent & $82(66)$ & $43(90)$ & & $(0,82-60)$ \\
\hline
\end{tabular}

\section{Source: Own elaboration}

No significant differences were found in terms of risk-health behaviors between both sexes, except in eating habits, where men had a higher prevalence of obesity than women (52\% vs $22 \%$ ) (Table $3)$.

Table 2.3 Gender and health risk behaviors

\begin{tabular}{|c|c|c|c|}
\hline Variable & $\begin{array}{r}\text { Feminine } \\
n(\%)\end{array}$ & $\begin{array}{l}\text { Masculine } \\
\text { n (\%) }\end{array}$ & $\mathbf{p}$ \\
\hline \multicolumn{4}{|l|}{ Sedentarism } \\
\hline Present & $71(57)$ & $26(54)$ & \multirow[t]{2}{*}{0,755} \\
\hline Absent & $54(43)$ & $22(46)$ & \\
\hline \multicolumn{4}{|l|}{ Smoking } \\
\hline Present & $0(0)$ & $1(2)$ & \multirow[t]{2}{*}{0,277} \\
\hline Absent & $125(0)$ & $47(98)$ & \\
\hline \multicolumn{4}{|c|}{ Excessive Alcohol Consumption } \\
\hline Present & $21(17)$ & $13(27)$ & \multirow[t]{2}{*}{0,128} \\
\hline Absent & $104(83)$ & $35(73)$ & \\
\hline \multicolumn{4}{|l|}{ BMI } \\
\hline Low Weight & $7(6)$ & $0(0)$ & \multirow[t]{3}{*}{$<0,001 * * *$} \\
\hline Normal Weight & $90(72)$ & $23(48)$ & \\
\hline $\begin{array}{l}\text { Overweight or } \\
\text { Obesity }\end{array}$ & $28(22)$ & $25(52)$ & \\
\hline
\end{tabular}




\subsection{Discussion}

The findings of the current study reveal an association between patterns of multiple unhealthy behaviors and mental health outcomes among college students, even though these unhealthy behaviors often cooccur and overlap. The data indicates that around $60 \%$ of medical students with unhealthy behaviors also suffered from anxiety, of which, a sedentary lifestyle (56\%), being overweight or obese $(30,7 \%)$ and alcohol consumption $(19,7 \%)$, were found to be the most prevalent unhealthy behaviors. Previous studies have compared health behaviors in students from health sciences and compared them to other students from different areas; these studies have found statistical significant differences in favor of better habits found students studying health sciences (Almutairi et al., 2018; Zarrazquin et al., 2014). Given these results, university students should be considered a priority challenge.

In accordance with the results obtained in the current study, other studies have also found that those with healthy habits are less likely to experience anxiety and depression. For example, Saneei and colleagues (2016) showed that individuals with healthier lifestyles were less likely to suffer from anxiety and depression (>95\%). In the same sense, another study revealed that adolescents with four or more health-risk behavior-were twice as likely to suffer from psychological issues, specifically anxiety or depression (Rao et al., 2015).

One of the most consistent findings of the scientific literature is that physical activity provides an undeniable benefit upon the improvement of symptoms related to anxiety and depression, thus it can even be considered as an effective treatment for these mental health problems (Belair, Kohen, Kingsbury, \& Colman, 2018; Kandola et al., 2018; Legey et al., 2017; Velten et al., 2018). One study revealed that even those individuals who report physical activity at least once a week have less risk of suffering from anxiety and depression when compared to individuals with a sedentary lifestyle (Belair et al., 2018). It should be noted that our results only showed significant differences between sedentary lifestyle and anxiety; however, no significant difference was found in relation to depression.

In agreement with the reports in literature (Johannessen, Andersson, Bjorngaard, \& Pape, 2017; Kenney, Anderson, \& Stein, 2018), the results of this study also showed a relationship between depression and alcohol consumption. It has been observed that higher levels of depression have been associated with the use of alcohol at an early age, and that this affects the female population more than the male population (Johannessen et al., 2017). Also, current issues, such as cyberbullying, also increase the risk of experiencing mental health problems (Selkie, Kota, Chan, \& Moreno, 2015).

Additionally, differences in psychological state were observed between both genders. The prevalence of anxiety (62\% vs. $46 \%$ ) and depression (34\% vs. 10\%) is higher in women than in men. Other studies have already reported this finding (Pacheco et al., 2014; Rao et al., 2015), attributing this increased risk to both socio-cultural issues and to physical and psychological experiences which are associated with gender (Pacheco et al., 2014).

On the other hand, the percentage of obesity or overweight was higher in men $(52 \%)$ than in women (22\%) (Alzahrani et al., 2019; D'Souza, Walls, Rojas, Everett, \& Wentzien, 2015; Kanikowska et al., 2017). Similar findings have been seen in other studies, for example, Alzahrani and his collaborators (2019) reported statistically significant differences in mean BMI with $26,9 \pm 5,2 \mathrm{~kg} / \mathrm{m}^{2}$ in men vs. $22,8 \pm 4,1 \mathrm{~kg} / \mathrm{m}^{2}$ in women. It has been observed that men are generally more physically active than women, but tend to have worse eating habits (Pacheco et al., 2014). It should be noted that the proportion of overweight and obese individuals in the sample of students is below the national average, which reports that 7 out of 10 Mexican adults are overweight or obese $(72,5 \%)$, and contrary to the findings of the present study, women $(75,6 \%)$ tend to have higher rates than men $(69,4 \%)$ (UribeCarvajal, Jiménez-Aguilar, Morales-Ruan, Salazar-Coronel, \& Shamah-Levy, 2018).

As previously stated, current medical students will be the future responsible for the promotion of healthy habits among the general population, in addition, the good habits practiced by these professionals have shown to influence in the lifestyle choices of their patients (Yu et al., 2015; Zarrazquin et al., 2014). Given these observations, student education should emphasize the importance of promoting healthy habits regarding self-care and the care of others, to prevent the development of chronic diseases, which are currently one of the biggest public health concerns in the world. 
It is recommended that future studies be carried out comparing students from different scientific disciplines, to better detect the different issues which may exist between these groups.

\subsection{Acknowledgments}

We appreciate the valuable participation of medical students from the Tonalá University Center belonging to the University of Guadalajara.

\subsection{Conclusions}

Medical students carry a large academic load which could potentially contribute to present a variety of risk factors against health. At the top of the list of risk factors are anxiety followed by depression, both of them are linked to sedentary lifestyle and overweight problems. In the other hand the gender plays an important role over the emotional state, since women's present highest prevalence of anxiety and depression.

Nowadays, students mental health becomes an apprehensive issue within the universities. Anxiety is the most common mental health problems in students, followed by depression. Medical schools are known to be a stressful environment that leads to negative effect on the students physical and psychological health. Long term follow-up of such study cohorts will be useful to educators, administrators and practitioner to inform efforts to optimize the health, safety, and efficiency of our future medical practitioners

\subsection{References}

Acosta-Rodríguez, F., Rivera-Martínez, M., \& Pulido-Rull, M. A. (2011). Depression and anxiety in a sample of unemployed Mexican individuals. Journal of Behavior, Health \& Social, 3(1), 35-42.

Almutairi, K. M., Alonazi, W. B., Vinluan, J. M., Almigbal, T. H., Batais, M. A., Alodhayani, A. A., et al. (2018). Health promoting lifestyle of university students in Saudi Arabia: a cross-sectional assessment. BMC Public Health, 18(1), 1093.

Alzahrani, S. H., Malik, A. A., Bashawri, J., Shaheen, S. A., Shaheen, M. M., Alsaib, A. A., et al. (2019). Health-promoting lifestyle profile and associated factors among medical students in a Saudi university. SAGE Open Med, 7, 2050312119838426.

Belair, M. A., Kohen, D. E., Kingsbury, M., \& Colman, I. (2018). Relationship between leisure time physical activity, sedentary behaviour and symptoms of depression and anxiety: evidence from a population-based sample of Canadian adolescents. BMJ Open, 8(10), e021119.

Cezaretto, A., Ferreira, S. R., Sharma, S., Sadeghirad, B., \& Kolahdooz, F. (2017). Impact of lifestyle interventions on depressive symptoms in individuals at-risk of, or with, type 2 diabetes mellitus: A systematic review and meta-analysis of randomized controlled trials. Nutr Metab Cardiovasc Dis, 26(8), 649-662.

D'Souza, M. J., Walls, K. J., Rojas, C., Everett, L. M., \& Wentzien, D. E. (2015). Effect of Gender and Lifestyle Behaviors On BMI Trends In A Sample Of The First State's Undergraduate Population. Am J Health Sci, 6(1), 59-74.

González, D. A., Reséndiz-Rodríguez, A., \& Reyes-Lagunes, I. (2015). Adaptation of the BDI-II in Mexico. Salud Mental 38(4), 237-244.

Hyakutake, A., Kamijo, T., Misawa, Y., Washizuka, S., Inaba, Y., Tsukahara, T., et al. (2016). Crosssectional observation of the relationship of depressive symptoms with lifestyles and parents' status among Japanese junior high school students. Environ Health Prev Med, 21(4), 265-273.

Johannessen, E. L., Andersson, H. W., Bjorngaard, J. H., \& Pape, K. (2017). Anxiety and depression symptoms and alcohol use among adolescents - a cross sectional study of Norwegian secondary school students. BMC Public Health, 17(1), 494. 
Kandola, A., Vancampfort, D., Herring, M., Rebar, A., Hallgren, M., Firth, J., et al. (2018). Moving to Beat Anxiety: Epidemiology and Therapeutic Issues with Physical Activity for Anxiety. Curr Psychiatry Rep, 20(8), 63.

Kanikowska, D., Sikorska, D., Kuczynska, B., Grzymislawski, M., Breborowicz, A., \& Witowski, J. (2017). Do medical students adhere to advice regarding a healthy lifestyle? A pilot study of BMI and some aspects of lifestyle in medical students in Poland. Adv Clin Exp Med, 26(9), 1391-1398.

Kenney, S. R., Anderson, B. J., \& Stein, M. D. (2018). Drinking to cope mediates the relationship between depression and alcohol risk: Different pathways for college and non-college young adults. Addict Behav, 80, 116-123.

Kim, E. G. (2018). Multilevel Analysis of the Risk Factors in High-Risk Health Behavior among Korean Adolescents. Osong Public Health Res Perspect, 9(1), 3-8.

Legey, S., Aquino, F., Lamego, M. K., Paes, F., Nardi, A. E., Neto, G. M., et al. (2017). Relationship Among Physical Activity Level, Mood and Anxiety States and Quality of Life in Physical Education Students. Clin Pract Epidemiol Ment Health, 13, 82-91.

Lolokote, S., Hidru, T. H., \& Li, X. (2017). Do socio-cultural factors influence college students' selfrated health status and health-promoting lifestyles? A cross-sectional multicenter study in Dalian, China. BMC Public Health, 17(1), 478.

Medina-Mora, M. E., Castro, S., Campillo-Serrano, C., \& Gómez-Mont, F. A. (1981). Validity and reliability of a high school drug use questionnaire among Mexican students. Bull Narc, 33(4), 67-76.

Mora-Rios, J., \& Natera, G. (2001). Expectations of alcohol consumption and associated problems in university students in Mexico City. Public Health of Mexico, 43, 89-96.

Moreno-Coutiño, A., \& Villalobos-Gallegos, L. (2017). Psychometric Properties of the Fagerstro “m Test for Nicotine Dependence in a Sample of Mexican Smokers. J Addict Nurs, 28(1), 27-33.

Nogueira, P. S., Ferreira, M. G., Rodrigues, P. R. M., Muraro, A. P., Pereira, L. P., \& Pereira, R. A. (2018). Longitudinal Study on the Lifestyle and Health of University Students (ELESEU): design, methodological procedures, and preliminary results. Cad Saude Publica, 34(4), e00145917.

Pacheco, R. L., Santos-Silva, D. A., Gordia, A. P., de Quadros, T. M., \& Petroski, E. L. (2014). Sociodemographic determinants of university students' lifestyles. Rev Salud Publica (Bogota), 16(3), 382-393.

Paz-Ballesteros, W. C., Zavala-Arciniega, L., Gutiérrez-Torres, D. S., Ponciano-Rodríguez, G., \& Reynales-Shigematsu, L. M. (2019). Evaluation of the physical and psychological dependence on tobacco in adult Mexican smokers, Encodat. Public Health of Mexico, 61, 136-146.

Rao, S., Shah, N., Jawed, N., Inam, S., \& Shafique, K. (2015). Nutritional and lifestyle risk behaviors and their association with mental health and violence among Pakistani adolescents: results from the National Survey of 4583 individuals. BMC Public Health, 15, 431.

Robles, R., Varela, R., Jurado, S., \& Páez, F. (2001). Mexican version of Beck's Anxiety Inventory: Psychometric Properties. Mexican Journal of Psychology, 18(2), 211-218.

Rodriguez-Gazquez, M. L. A., Chaparro-Hernandez, S., \& Gonzalez-Lopez, J. R. (2016). Lifestyles of nursing students from a Colombian public university. Invest Educ Enferm, 34(1), 94-103.

Saneei, P., Esmaillzadeh, A., Keshteli, A. H., Reza Roohafza, H., Afshar, H., Feizi, A., et al. (2016). Combined Healthy Lifestyle Is Inversely Associated with Psychological Disorders among Adults. PLoS One, 11(1), e0146888. 
Selkie, E. M., Kota, R., Chan, Y. F., \& Moreno, M. (2015). Cyberbullying, depression, and problem alcohol use in female college students: a multisite study. Cyberpsychol Behav Soc Netw, 18(2), 79-86.

Sharma, B., Nam, E. W., Kim, D., Yoon, Y. M., Kim, Y., \& Kim, H. Y. (2016). Role of gender, family, lifestyle and psychological factors in self-rated health among urban adolescents in Peru: a school-based cross-sectional survey. BMJ Open, 6(2), e010149.

Uribe-Carvajal, R., Jiménez-Aguilar, A., Morales-Ruan, M. D. C., Salazar-Coronel, A. A., \& ShamahLevy, T. (2018). Perception of body weight and the probability of developing obesity in Mexican adults. Public Health of Mexico,60, 254-262.

Velten, J., Bieda, A., Scholten, S., Wannemuller, A., \& Margraf, J. (2018). Lifestyle choices and mental health: a longitudinal survey with German and Chinese students. BMC Public Health, 18(1), 632.

Yu, Y., Yang, Y., Li, Z., Zhou, B., Zhao, Y., Yuan, S., et al. (2015). The association between medical students' lifestyles and their attitudes towards preventive counseling in different countries. BMC Public Health, 15, 1124.

Zarrazquin, I., Torres-Unda, J., Ruiz, F., Irazusta, J., Kortajarena, M., Hoyos Cillero, I., et al. (2014). Longitudinal study: lifestyle and cardiovascular health in health science students. Nutr Hosp, 30(5), 1144-1151. 